\title{
Indoleamine-2,3-Dioxygenase in Thyroid Cancer Cells Suppresses Natural Killer Cell Function by Inhibiting NKG2D and NKp46 Expression via STAT Signaling Pathways
}

\author{
Arum Park 1,2 ${ }^{1 D}$, Yunjeong Yang 1,3 ${ }^{(D)}$, Yunhee Lee 1,3 ${ }^{1}$, Mi Sun Kim ${ }^{1}$, Young-Jun Park ${ }^{1,2}$, \\ Haiyoung Jung 1,2 ${ }^{1 D}$, Tae-Don Kim ${ }^{1,2}$, Hee Gu Lee ${ }^{1,2}$, Inpyo Choi ${ }^{1,2, *}$ and Suk Ran Yoon ${ }^{1,2, *(\mathbb{D})}$ \\ 1 Immunotherapy Research Center, Korea Research Institute of Bioscience and Biotechnology, Yuseong-gu, \\ Daejeon 34141, Korea; sjllar@kribb.re.kr (A.P.); hike14@kribb.re.kr (Y.Y.); heeya@kribb.re.kr (Y.L.); \\ misun.kim1016@gmail.com (M.S.K.); pyj71@kribb.re.kr (Y.-J.P.); haiyoung@kribb.re.kr (H.J.); \\ tdkim@kribb.re.kr (T.-D.K.); hglee@kribb.re.kr (H.G.L.) \\ 2 Department of Functional Genomics, University of Science \& Technology, Daejeon 34113, Korea \\ 3 Department of Pharmacology, College of Pharmacy, Chungnam National University, Daejeon 34134, Korea \\ * $\quad$ Correspondence: ipchoi@kribb.re.kr (I.C.); sryoon@kribb.re.kr (S.R.Y.); Tel.: +82-42-860-4239 (I.C.); \\ Tel.: +82-42-860-4223 (S.R.Y.)
}

Received: 30 April 2019; Accepted: 7 June 2019; Published: 12 June 2019

\begin{abstract}
Natural killer (NK) cells are key players in the immune system. They use receptors on their cell surface to identify target cells. However, to escape being killed by the immune system, cancer cells such as thyroid cancer cells, use various methods to suppress the function of NK cells. Thus, this study aims to elucidate how thyroid cancer cells downregulate NK cell function in a co-culture system. We found that thyroid cancer cells suppress NK cell cytotoxicity and inhibit the expression of activating receptors, such as NKG2D and NKp46, by regulating indoleamine 2,3-dioxygenase (IDO). Also, thyroid cancer cells produce kynurenine using IDO, which causes NK cell dysfunction. Kynurenine enters NK cells via the aryl hydrocarbon receptor (AhR) on the surfaces of the NK cells, which decreases NK cell function and NK receptor expression via the signal transducer and activator of transcription (STAT) 1 and STAT3 pathways. In addition, STAT1 and STAT3 directly regulated the expression of NKG2D and NKp46 receptors by binding to the promoter region. Conclusively, NK cell function may be impaired in thyroid cancer patients by IDO-induced kynurenine production. This implies that IDO can be used as a target for thyroid cancer therapeutics aiming at improving NK cell function.
\end{abstract}

Keywords: NK cells; thyroid cancer cells; indoleamine 2,3-dioxygenase; kynurenine; NKG2D; NKp46; STAT1; STAT 3

\section{Introduction}

NK cells inhibit tumor cells through several pathways. Targets are either recognized and directly killed by released granules or antibody-dependent cellular cytotoxicity (ADCC), or indirectly killed by other immune cells that gather due to cytokine release by the NK cells [1-4]. Activating and inhibitory receptors of NK cells play an important role in the activation of NK cells [5]. NK cells use their receptors that interact with ligands of target cells to determine the fate of these cells. When ligands bind, these activating and inhibitory receptors cooperate and decide whether to exert NK cell cytotoxicity on target cells [6]. Some important NK activating receptors include NKG2D, DNAM1, natural cytotoxic receptors (NCR) (NKp46, NKp30, and NKp44), and CD16 which are involved in antibody-dependent cytotoxicity (ADCC) [7]. 
Despite their ability to directly remove cancer cells, NK cells in tumor environments do not easily access the tumor site or are inhibited by other factors released by cancers $[8,9]$. One of such factors, indoleamine 2,3-dioxygenase (IDO), is mainly involved in T cell immunosuppression and is known to help tumor growth. Interferon (IFN)- $\gamma$ has been known as an inducer of IDO mechanism [10]. IDO enables tumor cells to escape the immune system by producing kynurenine, a tryptophan metabolite that selectively impairs the growth and survival of T-cells in tumor microenvironments [11, 12]. Kynurenine is also known to be involved in the functional degradation of NK cells, but its mechanism of NK cell function downregulation remains unclear. Kynurenine enters the cells via AHR (aryl hydrocarbon receptor) [13]. It interacts and regulates signal transduction using several transcription factors, including signal transducer and activator of transcription (STAT)1, STAT3, STAT5, Pai-2, Sp1, c-maf, and Bach2, in certain cell types [14-18].

The JAK-STAT signaling pathway plays an important role in NK cells, as most cytokines that can activate or block NK cells are known to regulate it [19]. IL-2, a cytokine that plays an important role in NK cell proliferation and receptor expression, is known to activate STAT1, 3, and 5 [20]. It is known that STAT5 is activated by IL-15, and that STAT1 and 3 are activated by IL-21, which leads to maturation, proliferation, and activation of NK cells [21,22]. In addition, various types of STAT signals are known to be involved in the maturation, cytotoxicity, or survival of NK cells [23-26].

This study aims to investigate the immunosuppressive mechanisms that could affect NK cell function in the thyroid cancer microenvironment. Previous studies have examined with supernatant of papillary thyroid cancer (PTC) cell line and anaplastic thyroid cancer (ATC) cell lines to examine the differences in prognosis of thyroid cancer [27]. We examined the function of NK cells in co-culture with the thyroid cancer cells, to elucidate the factors and mechanisms responsible for the suppression of NK cell function and NK receptor expression. To date, restricted information is available on the effect of thyroid cancer cells on NK cells. These results could provide helpful tips for the development of effective cancer therapeutics that can improve NK cell function.

\section{Experimental Section}

\subsection{Cell Lines and Culture}

Thyroid cancer cell lines, including TPC-1, FRO, and 850-5C were purchased from American Type Culture Collection (ATCC, Manassas, VA, USA). FRO and 850-5C cells were cultured in Roswell Park Memorial Institute (RPMI) containing 10\% FBS (Welgene, Gyeongsan, Korea). TPC-1 cells were cultured in Dulbecco's Modified Eagle Medium (DMEM) containing 10\% Fetal Bovine Serum (FBS). In co-culture experiments, NK cells were cultured for $24 \mathrm{~h}$ with thyroid cancer cell lines in IL-2 $(10 \mathrm{ng} / \mathrm{mL})$ at a thyroid/NK ratio of 1:5 (thyroid cancer cells cultured $2 \times 10^{5}$ cells and NK cells cultured $1 \times 10^{6}$ cells per 6 well). 1-methyl-DL-tryptophan (1MT, an IDO inhibitor; Sigma-Aldrich, St. Louis, $\mathrm{MO}$, USA) was added at $2 \mathrm{mmol} / \mathrm{L}(2 \mathrm{mM})$ during co-incubation for $24 \mathrm{~h}$. A total of $2 \mu \mathrm{M}$ of NS398 (PGE2 inhibitors, Sigma-Aldrich) or anti- TGF- $\beta$ (Sigma-Aldrich) was added to the co-culture system. When indicated, the following specific reagents were added to NK cells; L-kynurenine, CH223191, JSI-124, Fludarabine (Sigma-Aldrich). Also, 293T cells were purchased from American Type Culture Collection (ATCC, Manassas, VA, USA) and were cultured in DMEM containing 10\% FBS. NK cell lines including NK92 and NK leukemia (NKL) were obtained from American Type Culture Collection (ATCC, Manassas, VA, USA). NK92 cells were cultured in $\alpha$-MEM containing $0.2 \mathrm{mM}$ inositol, $0.1 \mathrm{mM}$ 2- mercaptoethanol, $0.02 \mathrm{mM}$ folic acid, $100 \mathrm{U} / \mathrm{mL}$ recombinant IL-2, 12.5\% horse serum, $12.5 \%$ FBS. NKL cells were cultured in RPMI in the presence of 15\% FBS, $2 \mathrm{mM} \mathrm{L-glutamate,} 100 \mu \mathrm{g} / \mathrm{mL}$ penicillin, $100 \mu \mathrm{g} / \mathrm{mL}$ streptomycin, and $100 \mathrm{IU} / \mathrm{mL} \mathrm{IL}-2$.

\subsection{NK Cell Isolation and Culture}

Human NK cells were isolated from peripheral blood (PB) of a healthy donor. Rosette Sep (StemCell Technologies) was added into PB for elimination of CD3+ cells and red blood cells. Then NK 
cells were isolated using CD56 magnetic beads (Miltenyi Biotec, Bergisch Gladbach, Germany). A total of $1 \times 10^{6}$ CD56 cells per 24 well were cultured in $\alpha$-minimal essential medium (Welgene) supplemented with human IL-15 (10 ng/mL), IL-21 (10 ng/mL), and 10 ${ }^{-6} \mathrm{M}$ hydrocortisone (StemCell Technologies). All cytokines used for NK cell culture were purchased from PeproTech (Rocky Hill, NJ, USA). This study was approved by the Institutional Review Board of the Asan Medical Center according to the Bioethics and Safety Act and the Declaration of Helsinki. Each participant provided written, informed consent (Ethical code number: 10141091).

\subsection{Evaluation of NK Cell Cytotoxicity}

Cytotoxicity was evaluated using a calcein-AM release assay [28]. Briefly, target cells were labeled with calcein-AM (Invitrogen, Carlsbad, CA, USA) for $1 \mathrm{~h}$. Calcein-labeled target cells $(1 \times$ $10^{4}$ cells per well) and serially diluted effector cells were then co-cultured in 96-well round-bottom plates for $4 \mathrm{~h}$. "Maximum release" was simulated by adding $2 \%$ Triton X-100 to the target cells, and "spontaneous release" was simulated by adding culture media to the target cells. The calcein released into the supernatant was measured using a multi-mode microplate reader (Molecular Devices, San Jose, CA, USA). The percent specific lysis was calculated according to the formula ((test release-spontaneous release)/(maximum release-spontaneous release) $) \times 100$.

\subsection{Flow Cytometry Analysis}

NK cells were stained with indicated antibodies for further analysis. For immunostaining, the cells were washed two times with phosphate-buffered saline containing $2 \%$ fetal bovine serum, adjusted to approximately $1 \times 10^{5}$ to $1 \times 10^{6}$ cells in $100 \mu \mathrm{L}$ of the same buffer, and labeled with FITC-anti-CD158a, PE-anti-CD158b, BV-anti-CD56, APC-anti-NKp46, PE-anti-NKp44, FITC-anti-CD16, APC-anti-NKp30, FITC-anti-CD158e, PE-anti-NKG2D, PE-anti-TRAIL, or PE-anti-AhR. Incubations with antibodies were performed for $25 \mathrm{~min}$ at $4{ }^{\circ} \mathrm{C}$ in the dark. Antibodies for immunostaining were purchased from BD Bioscience. The data of samples were acquired by Canto II (BD Bioscience, Franklin Lakes, NJ, USA) and analyzed using software Flow Jo (Tree Star, Inc., Ashland, OR, USA).

\subsection{IFN- $\gamma$ and Kynurenine Measurement}

Interferon- $\gamma($ IFN- $\gamma)$ was evaluated in the NK cell supernatant obtained from the co-culture with thyroid cancer cells by specific enzyme-linked immunosorbent assay (ELISA) kit purchased from eBioscience (Waltham, MA, USA). Kynurenine was measured in the thyroid cancer cell supernatant obtained from the co-culture with NK cells. A total of $60 \mu \mathrm{L}$ of sample/standard and $30 \mu \mathrm{L}$ of $30 \%$ trichloroacetic acid (Sigma-Aldrich, St. Louis, MO, USA) were incubated for $30 \mathrm{~min}$ at $50^{\circ} \mathrm{C}$ in 96 -well round-bottom culture plate to hydrolyze $\mathrm{N}$-formyl kynurenine to kynurenine. The 96 -well plates were centrifuged at $3000 \times g$ for $10 \mathrm{~min}$ and $70 \mu \mathrm{L}$ of supernatant was obtained. Equal amounts of Ehrlich Reagent (2\% p-dimethylaminobenzaldehyde in glacial acetic acid) were added to the supernatants for reaction. Absorbance was read at $492 \mathrm{~nm}$.

\subsection{Western Blot Analysis}

To measure IDO levels in thyroid cancer cells, aliquots of $5 \times 10^{5}$ cancer cells were incubated at $37^{\circ} \mathrm{C}$ for $48 \mathrm{~h}$ untreated or treated with IFN- $\gamma 10 \mathrm{ng} / \mathrm{mL}$ or co-cultured with NK cells $\left(1 \times 10^{6}\right)$. The thyroid cancer cells were treated with 1 or $2 \mathrm{mM}$ of 1 MT for blocking the IDO expression stimulated by IFN- $\gamma$. Cell lysis was carried out by radioimmunoprecipitation using assay cell lysis buffer (GenDEPOT, Katy, TX, USA) with protease inhibitor. Samples were separated by $9 \%$ Sodium Dodecyl Sulfate Polyacrylamide Gel Electrophoresis (SDS-PAGE) and transferred onto $0.45 \mu \mathrm{m}$-pore polyvinylidene difluoride membranes (Millipore, Bedford, MA). After $1 \mathrm{~h}$ of blocking in PBS supplemented with $0.05 \%$ Tween 20 (Duchefa Biochemie, NH, Netherlands) containing 5\% skimmed milk at room temperature, the membranes were incubated overnight with primary antibodies at $4{ }^{\circ} \mathrm{C}$. The primary antibodies used were $\beta$-actin (Santa Cruz Biotechnology, CA, USA) or IDO (Cell Signaling Technology, Danvers, 
MA, USA). Subsequently, the membranes were incubated with corresponding Horseradish peroxidase (HRP) conjugated anti-rabbit, anti-mouse antibody (Santa Cruz Biotechnology, CA, USA) for $1 \mathrm{~h}$ at room temperature.

For NK signaling pathway analysis, $1 \times 10^{6} \mathrm{NK}$ cells were cultured with indicated concentrations of kynurenine at $37^{\circ} \mathrm{C}$ for $24 \mathrm{~h}$ and then lysed in lysis buffer. $293 \mathrm{~T}$ and NK cell lines including NK 92 and NKL were cultured in a condition media $\left(2 \times 10^{5}\right.$ to $5 \times 10^{5}$ cells per 6-well plates). Primary antibodies against STAT1 (42H3), phosphorylated (p-) STAT1, STAT3 (124H6) and p-STAT3 were purchased from Cell Signaling Technology.

The Western blot bands were detected with luminol/enhancer solution and stable peroxide solution (Thermo Fisher Scientific, MA, USA). The intensity of each band was obtained using the program CSAnalyzer 4 (ATTO Technology, NY, USA) and normalized to $\beta$-actin. Fold change was used to compare the relative abundance of a target protein to the control sample on the same membrane.

\subsection{Quantitative Real-Time PCR}

Total RNA was extracted using the RNeasy ${ }^{\circledR}$ Mini kit (Qiagen, Hilden, Germany) according to the manufacturer's instructions. Total RNA was reverse-transcribed using cDNA synthesis kit (Toyobo, Osaka, Japan), and real-time PCR was performed in a Dice TP 800 Thermal Cyclear with SYBR ${ }^{\circledR}$ Premix (Takara Co., Shiga, Japan). Real-time PCR reactions were carried out in a $18 \mu \mathrm{L}$ volume containing $10 \mathrm{pmol} / \mu \mathrm{L}$ primers and $1 \mu \mathrm{L}$ cDNA using the following conditions: one cycle of $95^{\circ} \mathrm{C}$ for $30 \mathrm{~s}, 40$ cycles of $95^{\circ} \mathrm{C}$ for $5 \mathrm{~s}$, and $60^{\circ} \mathrm{C}$ for $10 \mathrm{~s}$; and a dissociation stage of 1 cycle at $95^{\circ} \mathrm{C}$ for $15 \mathrm{~s}, 60^{\circ} \mathrm{C}$ for $30 \mathrm{~s}$, and $95^{\circ} \mathrm{C}$ for $15 \mathrm{~s}$. Results were normalized to the housekeeping genes GAPDH. Gene expression values were calculated with the $2^{-\Delta \Delta C t}$ method. Relative quantification of gene expression was determined by comparison of fold value. The primer sequences were as follows; for AhR 5' -CAACAGCAACAGTCCTTGGC-3' and 5'-GTTGCTGTGGCTCCACTACT-3' ; for GAPDH 5'-GCACCGTCAAGGCTGAGAAC-3' and 5'-TGGTGAAGACGCCAGTGGA-3' .

\subsection{Luciferase Assay}

To generate NKG2D promoter-pGL3 or NKp46 promoter-pGL3, human NKG2D and NKp46 promoter sequences were amplified from human NK cell genomic DNA by PCR with specific primers. Promoter primers were designed using Takara in-fusion-cloning-tools (https://www.takarabio.com). The sequences were as follows: For NKp46 5'-TTTCTCTATCGATAGGTTGGGACTACAGGCATGTGC-3' and 5' -CCGGAATGCCAAGC TCGCTCAGATTCTGCCGGC-3'; for NKG2D 5'-TTTCTCTATCGATAG GGTCA ATGGGTACAAAGT-3' and $5^{\prime}$-CCGGAATGCCAAGCTAATAATGTAAAGATTTAAAAATAGT- $3^{\prime}$. The products were cloned into the BamHI and AvaI restriction enzyme sites of the pGL3-basic vector (Promega, Madison, WI, USA). STAT1 and STAT3-pOTB7 recombined vectors were provided from Korea Human Gene Bank (Medical Genomics Research center, KRIBB, Korea). A total of $2 \times 10^{5}$ 293T cells were seeded in the 24-well plates and were transfected the next day with Lipofectamine and PLUS reagent (Invitrogen ${ }^{\mathrm{TM}}$, Waltham, MA, USA) according to the instructions provided by the manufacturer. Recombinant pGL3 plasmids or pGL3-basic and STAT-OTB7 plasmids were transfected into the corresponding wells and pRL-TK vector containing the Renilla luciferase gene as an internal control was added to each well. The cells were lysed in standard $1 \times$ lysis buffer and the cell lysates were assayed for both firefly and Renilla luciferase activity using the luciferase reporter assay kit (Promega) according to the instructions provided by the manufacturer.

\subsection{Statistical Analysis}

Statistical significance was evaluated by Student's $t$-test using GraphPad prism software and Microsoft Excel. A P value of less than $0.05\left({ }^{*}\right)$, less than $0.01\left({ }^{* *}\right)$, or less than $0.001\left(^{* * *}\right)$ was considered statistically significant. 


\section{Results}

\subsection{Thyroid Cancer Cells Inhibit NK Cell Cytolytic Function and NK Receptor Expression}

NK cells were collected and analyzed after co-culture with thyroid cancer cells. The cytolytic function of NK cells decreased after co-culture with thyroid cancer cells, even though the level was depended on the thyroid cancer cells in the co-culture (Figure 1A,B). The percentage of positive cells expressing NK cell receptors especially activating receptors such as, NKp46, CD16, NKp30, and NKG2D, also decreased after co-culture. The expression of the death receptor TRAIL was also significantly decreased (Figure 1C). These results indicate that the interaction with thyroid cancer cells resulted in reduced NK activating receptors, which suppressed NK cell cytotoxicity.

A.

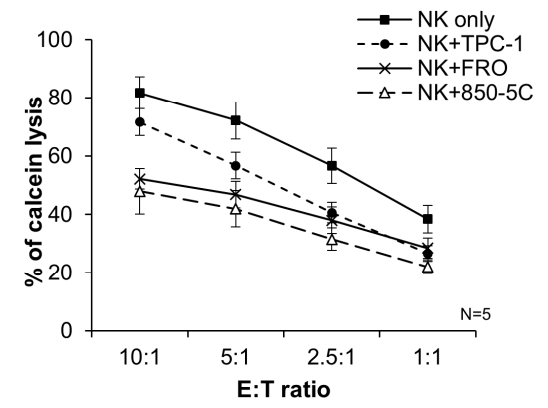

B.

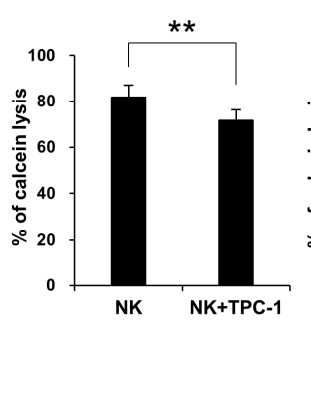

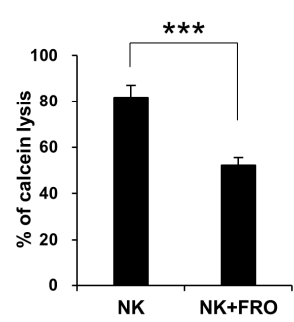

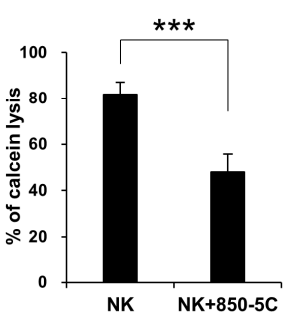

C.

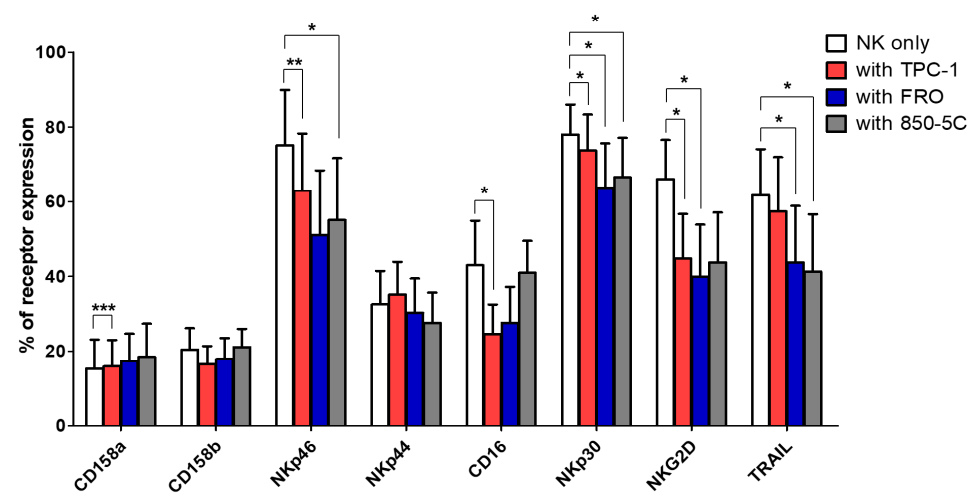

Figure 1. Thyroid cancer cells inhibit natural killer (NK) cell cytotoxicity and NK receptor expression. (A) NK cells were cultured without thyroid cancer cells (square) or co-cultured with TPC-1 (circle), FRO (cross), and 850-5C (triangle) in the medium containing IL-2 for $24 \mathrm{~h}$. The cytotoxicity of NK cells was assessed against $\mathrm{K} 562$ cells at different E:T ratio as described in Materials and Methods. Bars represent mean \pm SD from five experiments. (B) Graphs of NK cell cytotoxicity cultured with each thyroid cancer cells relative to NK cells grown in control medium were shown. K562 cells were used as targets and the effector: target (E: T) ratio was 10:1. Bars represent mean \pm SD of five independent experiments. Statistical analyses were performed using the paired two-tailed Student's $t$-test. (C) Expressions of NK receptors were analyzed by flow cytometry. Graph indicates that the percent of NK receptor expressions in CD56 positive cells. Bars represent mean \pm SD of six independent experiments. Statistical analyses were performed using the paired two-tailed Student's $t$-test. ${ }^{*} P<0.05$, ${ }^{* *} P<0.01$, and ${ }^{* * *} P<0.001$.

\subsection{IDO Expression in Thyroid Cancer Cells is Induced by Co-Culture With NK Cells}

Previous reports showed that soluble factors from cancer cells could inhibit NK cell function [29-31]. We examined changes in NK cell function by inhibiting each factor (TGF- $\beta$ or PGE2 or IDO) in the co-culture environment using their inhibitors (Supplementary Figure S1). Only the inhibitor of IDO partially restored NK cell function. IDO is one of the factors known to be expressed by many cancers to aid their escape from the immune system. First, we examined NK cell cytotoxicity during treatment with an IDO inhibitor (1MT) in a co-cultured environment. The cytolytic activity of NK cells was 
decreased when NK cells were cultured with thyroid cancer cells, but it partially restored when NK cells were co-cultured with thyroid cancer cells and treated with 1MT (an IDO inhibitor). ATC-derived cells FRO and 850-5C similarly decreased NK activity and were affected by IDO inhibitors. (Figure 2A and Supplementary Figure S2). Treatment with 1MT also restored NK receptor expression in NK cells, which was reduced by co-culture with thyroid cancer cells (Figure 2B). IDO was not expressed in thyroid cancer cells cultured alone, but its expression was induced by treatment with IFN- $\gamma$ or co-culture with NK cells (Figure 2C). IFN- $\gamma$ was produced in the co-culture of NK cells and thyroid cancer cells (Figure 2D), which indicates that IFN- $\gamma$ produced in co-culture conditions induces IDO expression in thyroid cancer cells. As shown Figure 2E, IDO expression was not induced during treatment with 1MT, despite the stimulation of IFN- $\gamma$. In addition, we examined the production of kynurenine, a metabolite of IDO, known to downregulate NK cell function in culture supernatant. Its levels were very low when thyroid cancer cells were cultured alone, but significantly increased when they were cultured with NK cells (Figure 2F). These results suggest that thyroid cancer cells reduced NK cell cytolytic activity and expression of NK activating receptors by producing kynurenine using IDO. 
A.
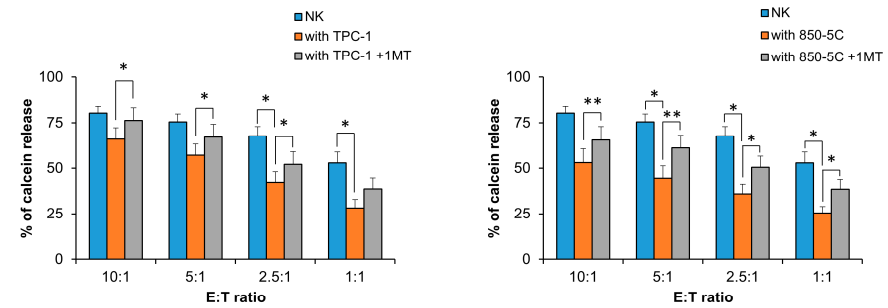

B.
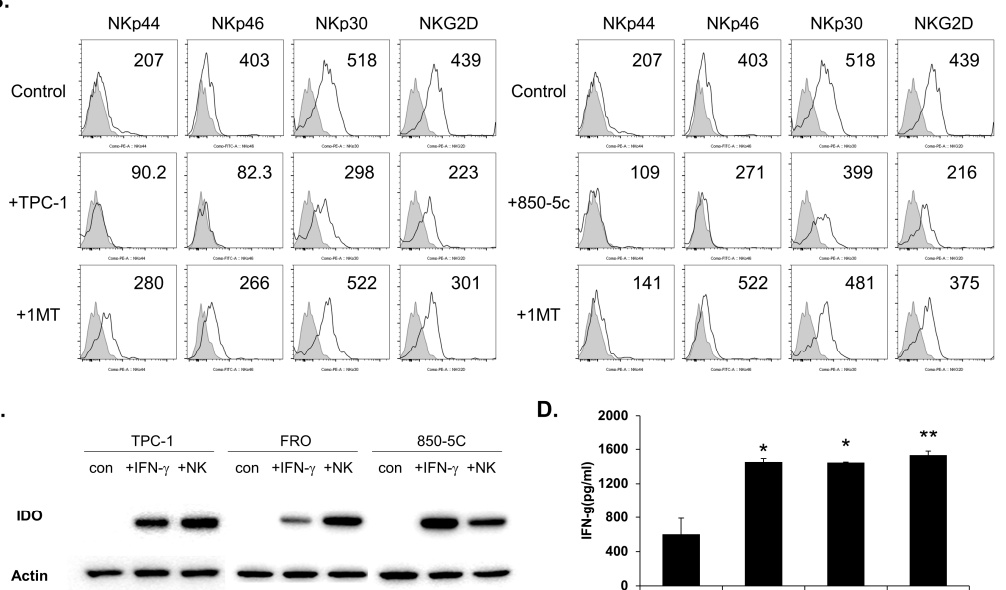

D.

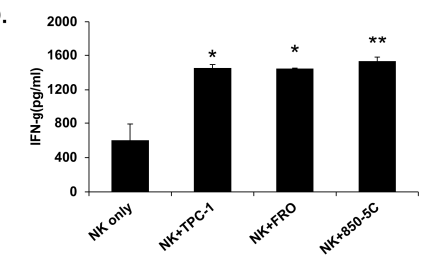

E.
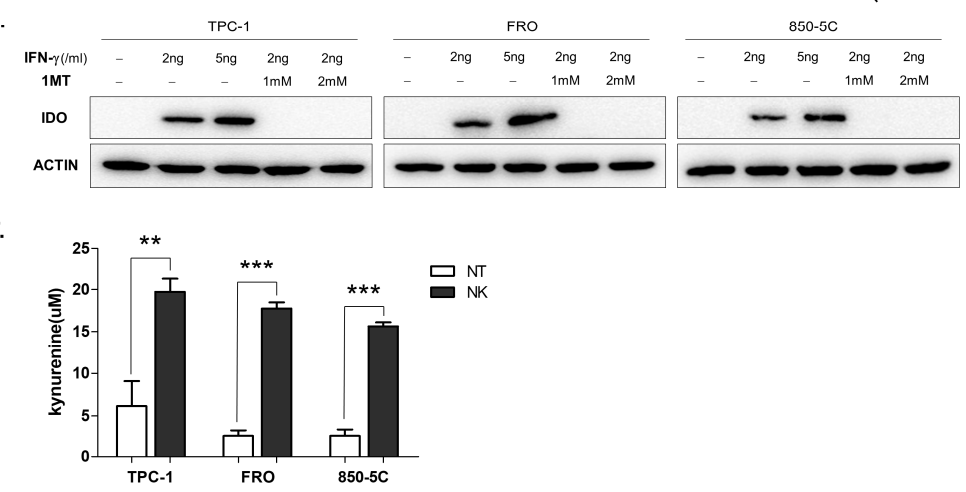

Figure 2. Indoleamine 2,3-dioxygenase (IDO) inhibitor, 1MT (1-Methyl-D-tryptophan) blocks IDO expression and restores NK cell activity reduced by thyroid cancer. (A) NK cells were cultured for $24 \mathrm{~h}$ with IL-2 either alone (blue) or with the indicated thyroid cancer cells. NK/thyroid cell co-cultures were set either in the absence (orange) or in the presence (gray) of IDO inhibitor. Bars represent mean \pm SD of five independent experiments. (B) Expressions of NK receptors, NKp44, NKp46, NKp30, and NKG2D (white profiles) and isotype controls (gray filled profiles) were analyzed by flow cytometry. Numbers indicate mean fluorescence intensity (MFI) and Y-axis shows cell counts. Control indicated NK cultured alone and +TPC or $+850-5 \mathrm{C}$ indicated NK cells cultured with thyroid cancer cells. +1MT indicated NK cells cultured with thyroid cancer cells in the presence of IDO inhibitor. (C) IDO expression was detected by Western blotting in thyroid cancer cells; untreated thyroid cancer cells, IFN- $\gamma$-treated thyroid cancer cells and thyroid cancer cells co-cultured with NK cells. $\beta$-actin served as a loading control. (D) IFN- $\gamma$ concentration in culture supernatants from NK cell co-cultured with the indicated thyroid cancer cells. Bars represent mean \pm SD of three independent experiments. Statistical analyses were performed in comparison with NK only group using the paired two-tailed Student's $t$-test. (E) The expression of IDO enzyme was assessed by Western blot analysis on untreated, IFN- $\gamma$-treated thyroid cancer cells with 2 ng or 5 ng per m, 1MT-treated thyroid cancer cells with $1 \mathrm{mM}$ or $2 \mathrm{mM}$. (F) L-kynurenine concentration was measured in culture supernatants from thyroid cancer cells only (NT, white), and thyroid cancer cells co-cultured with NK cells (dark gray). Bars represent means \pm SD obtained from six independent experiments. Statistical analyses were performed using the paired two-tailed Student's $t$-test. ${ }^{*} P<0.05,{ }^{* *} P<0.01$, and ${ }^{* * *} P<0.001$. 


\subsection{Kynurenine Inhibits NK Cell Activity via STAT Signaling Pathways.}

We treated NK cells with kynurenine and observed the mechanism responsible for its reduction of NK cell function. NK cells were treated with different concentrations of kynurenine, and their cytolytic activity against K562 was measured. The cytolytic activity of NK cells was decreased in a dose-dependent manner (Figure 3A). NK cells treated with kynurenine showed decreased cytolytic activity against thyroid cancer cells as well (Supplementary Figure S3). The expression of activating receptors by NK cells was also decreased, a similar pattern to that obtained when NK cells were co-cultured with thyroid cancer cells. The expression of NKp46 and NKG2D tended to decrease as the concentration of kynurenine increased, compared with the expression of the other receptors (Figure 3B). Next, we performed Western blotting for analysis of transcription factors known to be involved in NK cell activation, to identify the signaling pathway responsible for NK cell function decrease by kynurenine. Treatment with kynurenine dose-dependently decreased the quantity of the phosphorylated forms of STAT3 and STAT1 (Figure 3C,D), but not the activation of the other factors associated with NK activity such as NF- $\mathrm{kB}$ (nuclear factor kappa-light-chain-enhancer of activated B cells), p38 and ERK (extracellular-signal-regulated kinase) (Supplementary Figure S4). These results indicate that kynurenine produced by IDO in thyroid cancer cells inhibits the function of NK cells by downregulating STAT3 and STAT1 activation, which may also be related to the expression of NKp46 and NKG2D.

A.

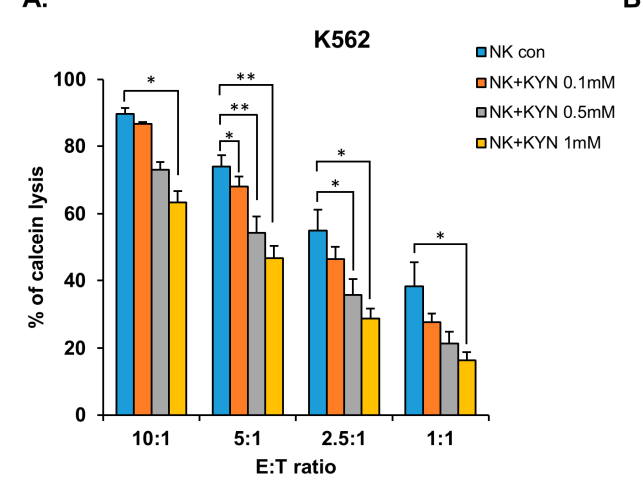

B.
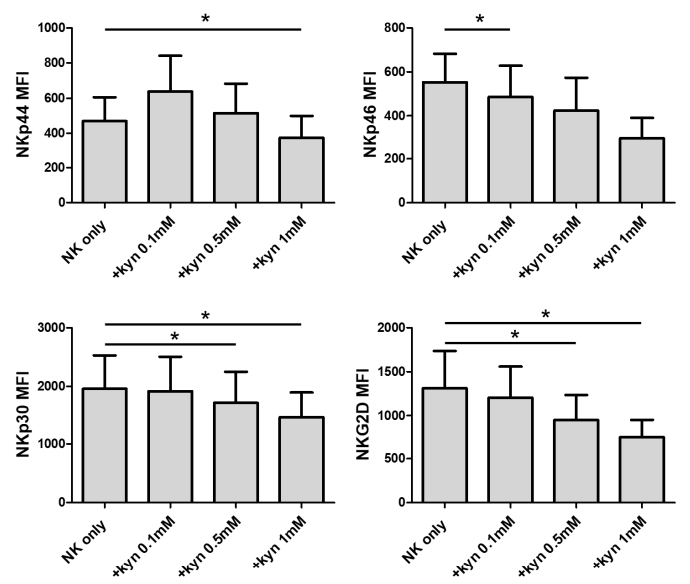

c.

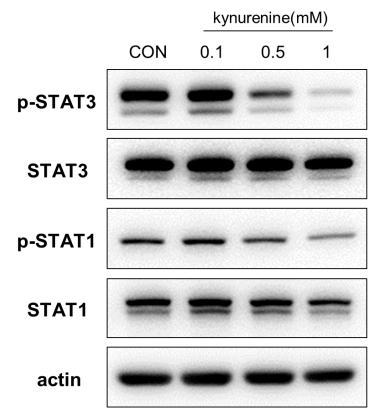

D.

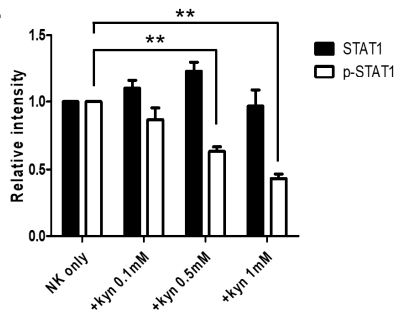

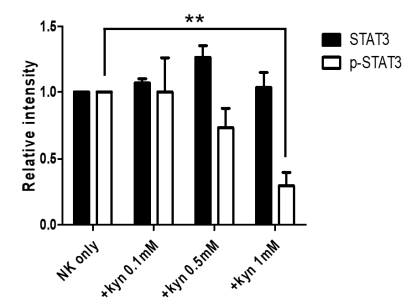

Figure 3. Kynurenine directly inhibits NK cell activity and NK receptor expressions. (A) NK cells were cultured with IL-2 in the absence (blue) or presence of $0.1 \mathrm{mM}$ (orange) or $0.5 \mathrm{mM}$ (gray) or $1 \mathrm{mM}$ (yellow) of L-kynurenine for $24 \mathrm{~h}$ and cytotoxicity against K562 cells was examined. Bars represent mean \pm SD of three independent experiments. (B) Expressions of NK receptors, including NKp44, NKp46, NKp30, and NKG2D were detected by flow cytometry. Graphs represent mean values of mean fluorescence intensity (MFI) for three independent experiments. (C) Phosphorylation of signal transducer and activator of transcription (STAT) 1 and STAT3 were analyzed by Western blotting after the treatment of kynurenine in NK cells. $\beta$-actin served as a loading control. (D) Relative intensity is defined as the intensity of the target protein normalized to $\beta$-actin. Bars represent mean \pm SD of three independent experiments. Statistical analyses were performed using the paired two-tailed Student's t-test. ${ }^{*} P<0.05$ and ${ }^{* *} P<0.01$. 


\subsection{Kynurenine Affects NK Cell Activity Through the Aryl Hydrocarbon Receptor (AhR)}

We examined the pathway through which kynurenine enters NK cells. First, we checked mRNA expression and surface expression of AhR, known as the kynurenine receptor in NK cells (Figure 4A,B). AhR expression was detected in NK cells and AhR mRNA levels increased in kynurenine treatment, though not in a dose-dependent manner. However, kynurenine treatment did not affect cell protein expression. We used the AhR antagonist $\mathrm{CH} 223191$ to determine if kynurenine affects NK cells by using AhR expressed on NK cells. The cytolytic activity of NK cells, and expression of NKG2D and NKp46 were restored by pretreatment with $1 \mu \mathrm{M}$ or $10 \mu \mathrm{M}$ CH223191 (Figure 4C,D). The changes in NK cells resulting from kynurenine inhibition by $\mathrm{CH} 223191$ were analyzed. Western blot analysis revealed that the signals for the activation of STAT3 and STAT1 were blocked when NK cells were treated with kynurenine. Also, blocking of AhR resulted in the activation of the STAT3/1 pathway (Figure 4E and Supplementary Figure S5). These results indicate that kynurenine decreases the cytolytic function of NK cells and activation of STAT signals via the AhR expressed on NK cells.

A.

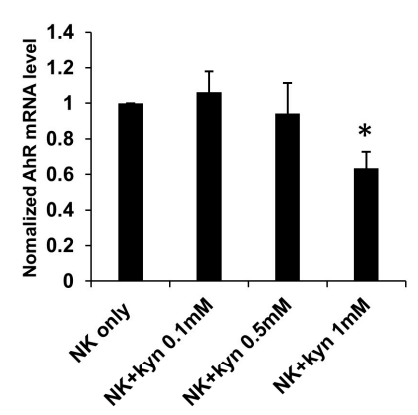

D.

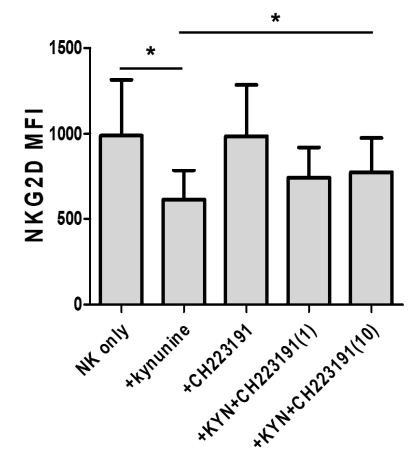

B.

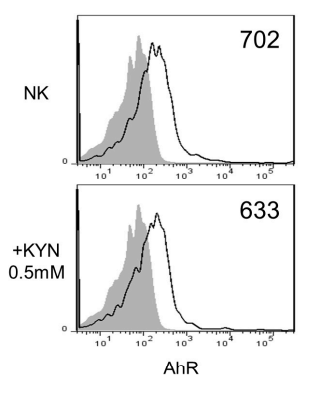

C.

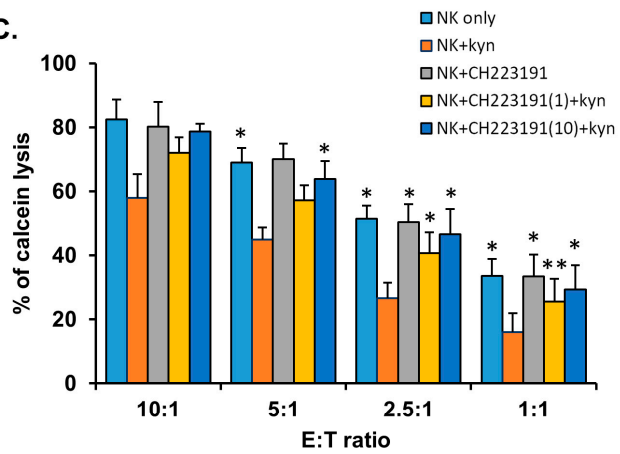

E.

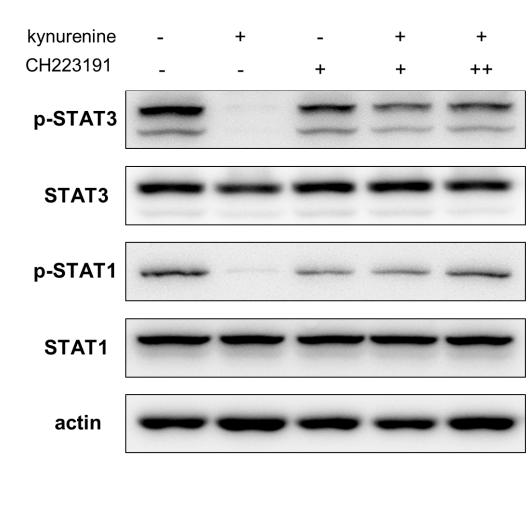

Figure 4. Kynurenine inhibits NK cell activity through aryl hydrocarbon receptor (AhR). mRNA level (A) and surface expression (B) of AhR were analyzed in kynurenine-treated or untreated NK cells. (C) NK cells were cultured with IL-2 in the absence (blue) or presence of indicated component for $24 \mathrm{~h}$ and cytotoxicity against K562 cells was examined; L-kynurenine (orange), CH223191(gray), kynurenine with $\mathrm{CH} 223191$ (yellow and dark blue). Bars represent mean \pm SD of three independent experiments. (D) Expressions of NK receptors, NKG2D, and NKp46 were analyzed by flow cytometry. Graphs represent mean values of MFI for three independent experiments of receptors. (E) Phosphorylation of STAT-3 and 1 signals were examined by Western blotting in NK cells under the indicated conditions. $\beta$-actin served as a loading control. Statistical analyses were performed using the paired two-tailed Student's $t$-test. ${ }^{*} P<0.05$ and ${ }^{* *} P<0.01$.

\subsection{STATs Regulate NK Cytolytic Activity and Receptor Expression.}

Inhibitors of STAT3 (JSI-124) and STAT1 (fludarabine) signaling were used to investigate their roles in NK cell function decrease. The results showed that they decreased the cytolytic activity of NK cells. Co-treatment resulted in a larger decrease than monotherapy (Figure 5A), similar to the 
observation made after treatment with kynurenine (Figure 5B). Treatment with STAT inhibitors also resulted in decreased NKp46 and NKG2D expression (Figure 5C), as similarly observed in kynurenine treatment. These results confirmed that kynurenine regulates NK cells by using STAT1 and STAT3 signaling to modulate the expression of NK receptors such as, NKp46 and NKG2D. 
A.

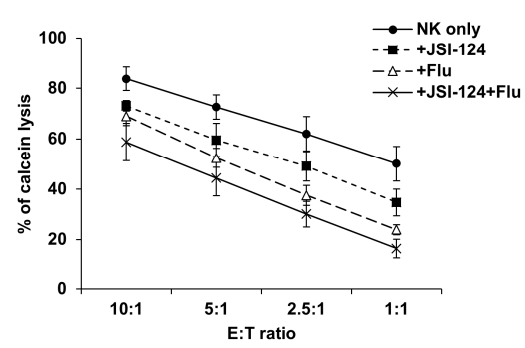

B.

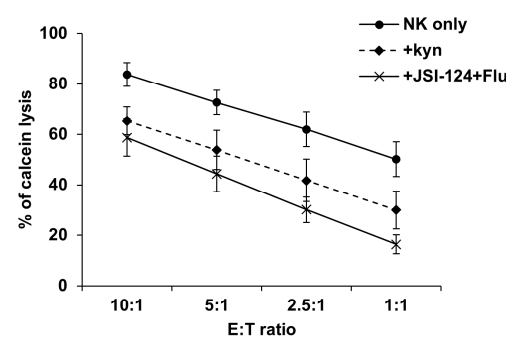

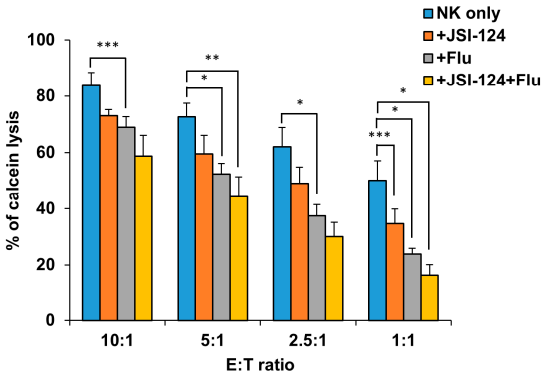

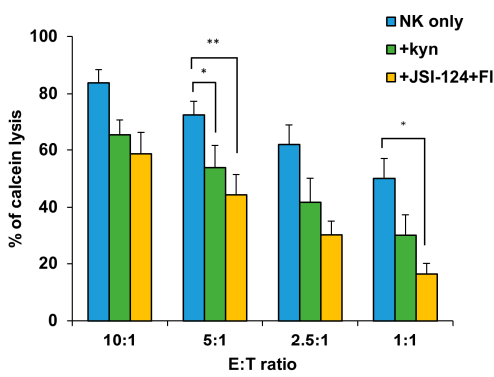

C.
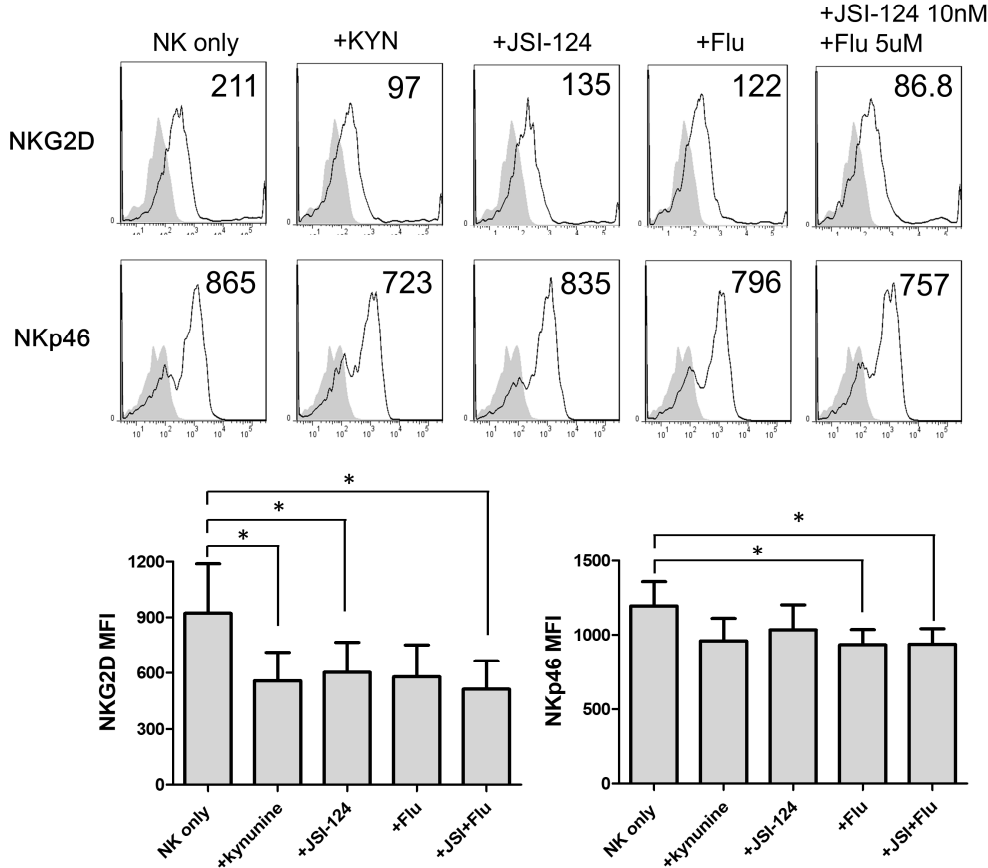

Figure 5. STATs signals regulate the activity of NK cells. (A) NK cells were cultured for $24 \mathrm{~h}$ with IL-2 either alone (left- circle, right- blue) or in the presence of the indicated inhibitor of STATs; STAT3 inhibitor (JSI-124, left-square, right-orange) or STAT1 inhibitor (fludarabine, left-triangle, right-gray) or both of them (left-cross, right-yellow). After $24 \mathrm{~h}$, the cytotoxicity of NK cells against K562 cells was examined (B) NK cells were treated with STAT inhibitors or kynurenine for $24 \mathrm{~h}$, and the cytotoxicity of NK cells against K562 was evaluated; circle indicates untreated NK cells (blue), diamond indicates NK cells treated with kynurenine (green) and cross indicates NK cells treated with STAT inhibitors (fludarabine+JSI-124, yellow). Bars represent mean \pm SD of three independent experiments. (C) Expression of NKG2D, NKp46 (white profiles), and isotype controls (gray filled profiles) were analyzed by flow cytometry. Numbers indicate mean fluorescence intensity and Y-axis shows cell counts. The graphs below represent mean values of MFI for four independent experiments. Statistical analyses were performed using the paired two-tailed Student's $t$-test. ${ }^{*} P<0.05,{ }^{* *} P<0.01$, and ${ }^{* * *} P<0.001$. 


\subsection{Direct Involvement of STATs in NK Receptor Expression}

NK receptor expression has been implicated in NK cell function. We assumed that the decreased expression of NK cell receptors such as, NKG2D and NKp46, resulted in the decreased NK cell function induced by kynurenine. Thus, we examined the effect of STAT1 and STAT3 regulated by kynurenine on NK cell receptor expression. We found that STAT1 and STAT3 mediate gene modulation effects by binding to specific target sequences in NK receptors. First, we checked the presence of the STAT1 and STAT3 binding motifs (TTCN ${ }_{2-4} \mathrm{GAA}$ ) in the promoter sequence of $\mathrm{NK}$ receptors using the program Find Individual Motif Occurences (FIMO) (http://meme-suite.org/tools/fimo), to confirm the possibility that the STATs regulate the expression of NK receptors. We obtained a sequence of promoters from the University of California Santa Cruz (UCSC) page (https://genome.ucsc.edu/), and were able to verify the presence of STATs motifs (Supplementary Figure S6). A pGL3 vector in which the promoter of each NK cell receptor containing the STAT binding motif was cloned, was used for the experiments. 293T cells were also used for the experiment because they were not only highly efficient in transfection, but also had low activation form of STAT3 and STAT1 (Figure 6A). To confirm the direct influence of STATs on NK cell receptor expression, a pGL3-NKp46 or pGL3-NKG2D vector containing the luciferase gene under the control of about 1-kb NKp46 or NKG2D promoter was transfected into 293T cells and luciferase activity was measured after $48 \mathrm{~h}$. At this time, a vector and a STAT1 or STAT3 clone were transfected with a promoter vector to stimulate a STAT signal, and a basic pGL3 vector was used as a control. Both STAT1 and STAT3 signals enhanced transcription of NKp46 and NKG2D. STAT1 showed a higher response to NKp46, and STAT3 showed a higher response in NKG2D (Figure 6B). These results indicate that the phosphorylated forms of STATs directly bind to the promoters of NK receptors (NKG2D or NKp46), which regulates the expression level of the receptor.

A.

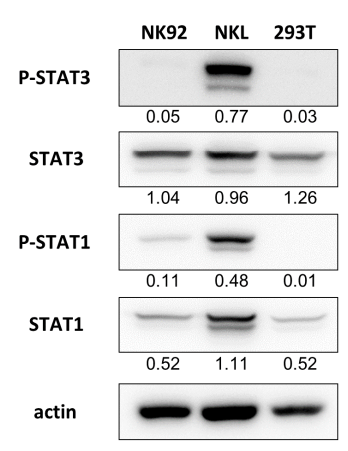

B.
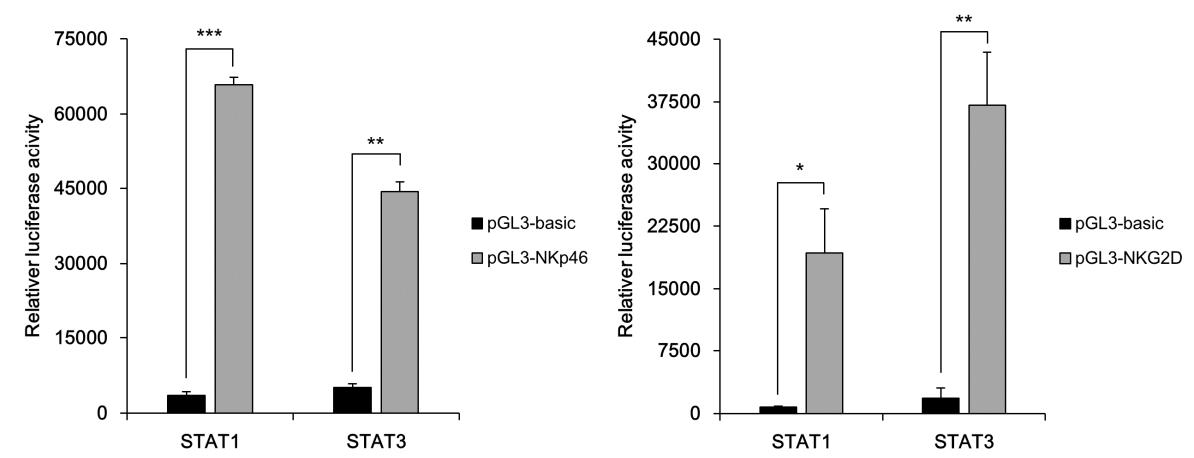

Figure 6. Expressions of NKG2D and NKp40 are directly regulated by STATs. (A) STAT 1 and STAT3 expressions were measured by Western blotting in indicated cell lines. The numbers below each band indicated quantitative analysis of target protein relative to $\beta$-actin. (B) 293T cells were transfected with the indicated vectors. After $48 \mathrm{~h}$, luciferase activity was quantified according to the manufacturer's protocol. The efficiency of transfection was calibrated to the Renila value. Bars represent mean \pm SD of three independent experiments. Statistical analyses were performed using the paired two-tailed Student's $t$-test. ${ }^{*} P<0.05,{ }^{* *} P<0.01$, and ${ }^{* * *} P<0.001$. 


\section{Discussion}

In this study, we demonstrated that thyroid cancer cells affect the function of NK cells by regulating indoleamine 2,3-dioxygenase (IDO) expression through the production of kynurenine. The expression of NKG2D and NKp46 receptors was especially downregulated by kynurenine treatment via STAT signaling pathways. In addition, we have newly found that STAT1 and STAT3 directly bind to the NKp46 and NKG2D promoters and regulate their expressions. The cytolytic ability of NK cells was decreased by co-culture with thyroid cancer cells. In particular, NK cells used in this study showed highly expressed activating receptors by stimulating cytokines such as IL-15, IL-21, and IL-2, but the expression of NK cell receptors decreased after co-culture. This may have resulted from the influence of several factors from the cancer microenvironments $[9,29,32]$. In our previous study, we investigated factors in thyroid cancer cell culture supernatant that could indirectly affect NK cells and found that PGE2 affected NK cells [27]. However, in the present study, treatment with PGE2 inhibitors had no effect on the reduced NK cell function induced by co-culture with thyroid cancer cells, suggesting that there may be other factors involved than PGE2 (Supplementary Figure S1); however, due to its ability to break down the essential amino acid tryptophan into kynurenine, its ability to aid immune system regulation of tumor growth has extensively been studied [33-35]. In addition, it has recently been reported that IDO catabolites block the proliferation of T and NK cells [36,37]. In the present study, blocking IDO in the co-culture system using its inhibitor 1MT, restored NK cell cytolytic activity and receptor (particularly NKp46 and NKG2D) expression. IDO production by thyroid cancer cells was induced by stimulation with IFN- $\gamma$ or co-culture with NK cells, and kynurenine production was also increased by co-culture with NK cells. Since kynurenine is known to directly affect many immune cells [38-40], we investigated if it directly affects NK cells. When NK cells were treated with kynurenine, NK cell receptor expression and cytolytic activity decreased (Figure 3A,B). The expression of NKp46 and NKG2D receptors was decreased by kynurenine, consistent with NK receptor expression decrease observed after co-culture with thyroid cancer cells, and they were both restored by treatment with the IDO inhibitor (Figure 2). These suggest that kynurenine produced by IDO directly impairs NK cell function. Kynurenine treatment led to the decreased phosphorylation of STAT1 and STAT3 in NK cells (Figure 3C). It has been reported that STAT signals are activated by IL-15, 21, and IL-2 in NK cells [41]. We found that kynurenine treatment reduced the expression of P-STATs in NK cells in a dose-dependent manner, indicating that kynurenine regulates NK cells via STATs signaling pathways. In addition to STAT1 and STAT3, we examined the change of other STAT family expression level by kynurenine. We examined the expression of STAT4 that is known to be binding to the promoter of IFN- $\gamma$, and the expression of STAT5 that is involved in the development and function of immune suppression of NK cells [23,42]. However, the expressions of STAT4 and 5 were not significantly changed by the treatment of kynurenine (Supplementary Figure S4).

Kynurenine has been known to enter cells through the aryl hydrocarbon receptor (AhR). AhR is activated or inactivated by ligands including kynurenine, and many chemical ligands. AhR acts as a transcription factor to control metabolic enzymes and is also known to be involved in immunity, stem cell maintenance, and cell differentiation [43-45]. Treatment with the AhR antagonist CH223191 recovered the impaired NK cell function induced by kynurenine treatment (Figure 4C). CH 223191 is an effective 2, 3, 7, 8-Tetrachlorodibenzo-p-dioxin (TCDD)-induced AhR inhibitor, that blocks the binding of TCDD to AhR, and prevents TCDD mediated nuclear transfer and AhR DNA binding [46,47]. These results demonstrate that kynurenine enters the NK cell via AhR. In addition, downregulation of STATs activation was restored by treatment with an AhR antagonist, which confirms that kynurenine regulates the STAT pathways through AhR (Figure 4).

In some cancer cells, STAT3 is known to escape NK cell immune surveillance by regulating NKG2D ligand expression. In addition, STAT3 plays a pivotal role in carcinogenesis and immunosuppression [48,49]. In contrast, recently, STAT3 signaling has been reported to promote the proliferation and function of human NK cells activated by IL-21 stimulation. In this study, we have elucidated a mechanism that regulates STAT pathways using IDO in NK cells, other than previously 
reported mechanisms that use cytokines. STAT signals were activated in NK cells used in this study, which could be caused by the cytokines IL-21 and IL-15 detected in the NK cell culture medium (Figures $3 \mathrm{C}$ and $4 \mathrm{E}$ ). We also showed the relationship between STAT and NKp46, and STAT and NKG2D. Both STAT1 and STAT3 signals enhanced transcription of NKp46 and NKG2D, with STAT1 showing a higher response to NKp46, and STAT3 showing a higher response in NKG2D. We also found that the cytolytic activity of NK cells was decreased by treatment with STAT1 and STAT3 inhibitors (Figures 5 and 6). By performing promoter assay, we confirmed that STATs bind to the promoter of NKG2D and NKp46 to activate transcription (Figure 6). The same palindromic core motif TTCN $_{2-4}$ GAA, was found in sequences recognized by all STATs [50-52]. Thus, activation of STAT3/1 in NK cells regulate receptor expression by direct binding to promoter of NK activating receptors.

\section{Conclusions}

In conclusion, IDO expression in thyroid cancer cells induced by interaction with NK cells in a tumor microenvironment may protect themselves from immune system surveillance through the suppression of NK cell function by producing kynurenine. Kynurenine decreases the cytolytic activity of NK cells, and NKG2D and NKp40 expression by downregulating the activation of the STAT1 and STAT3 pathways in NK cells. These data present the possibility that modulation of IDO could improve NK cell function in thyroid cancer therapy.

Supplementary Materials: The following are available online at http://www.mdpi.com/2077-0383/8/6/842/s1, Supplementary Figure S1: Effect of PGE2 and TGF- $\beta$ blockade on restoring NK activity in the co-culture system. Supplementary Figure S2: IDO inhibitor (1MT) partially restores NK cell activity and NK receptor expressions reduced by thyroid cancer. Supplementary Figure S3: Cytolytic activity of NK cells treated with kynurenine against thyroid cancer cells. Supplementary Figure S4: Western blot analysis of the activation of other signals related to NK activity. Supplementary Figure S5: Kynurenine inhibits STAT signals in NK cell through AhR. Supplementary Figure S6: Receptors of NK cells promoter sequences.

Author Contributions: A.P. performed experiments, analyzed data, and drafted the manuscript. Y.Y., Y.L., and M.S.K. assisted with some experiments. Y.-J.P., H.J., T.-D.K., and H.G.L. provided useful suggestions. I.C. and S.R.Y. supervised the study, helped to design the experiments, and wrote the manuscript.

Funding: This work was supported in part by the grants from Korea Institutes of Oriental Medicine (K17042), the grant of National Research Foundation of Korea (NRF) (2019R1A2C1007906 and 20191A2C3002034) and KRIBB Research Initiative Program from the Korea government.

Conflicts of Interest: The authors declare no conflict of interest. The funders had no role in the design of the study; in the collection, analyses, or interpretation of data; in the writing of the manuscript, or in the decision to publish the results.

\section{References}

1. Golden-Mason, L.; Rosen, H.R. Natural killer cells: Multifaceted players with key roles in hepatitis c immunity. Immunol. Rev. 2013, 255, 68-81. [CrossRef] [PubMed]

2. Vivier, E.; Tomasello, E.; Baratin, M.; Walzer, T.; Ugolini, S. Functions of natural killer cells. Nat. Immunol. 2008, 9, 503-510. [CrossRef] [PubMed]

3. Smyth, M.J.; Hayakawa, Y.; Takeda, K.; Yagita, H. New aspects of natural-killer-cell surveillance and therapy of cancer. Nat. Rev. Cancer 2002, 2, 850-861. [CrossRef] [PubMed]

4. O'Callaghan, C.A. Molecular basis of human natural killer cell recognition of hla-e (human leucocyte antigen-e) and its relevance to clearance of pathogen-infected and tumour cells. Clin. Sci. (Lond.) 2000, 99, 9-17. [CrossRef] [PubMed]

5. Chiossone, L.; Dumas, P.Y.; Vienne, M.; Vivier, E. Natural killer cells and other innate lymphoid cells in cancer. Nat. Rev. Immunol. 2018, 18, 671-688. [CrossRef] [PubMed]

6. Lanier, L.L. Nk cell receptors. Annu. Rev. Immunol. 1998, 16, 359-393. [CrossRef] [PubMed]

7. Kruse, P.H.; Matta, J.; Ugolini, S.; Vivier, E. Natural cytotoxicity receptors and their ligands. Immunol. Cell Biol. 2014, 92, 221-229. [CrossRef]

8. Rabinovich, G.A.; Gabrilovich, D.; Sotomayor, E.M. Immunosuppressive strategies that are mediated by tumor cells. Annu. Rev. Immunol. 2007, 25, 267-296. [CrossRef] 
9. Balsamo, M.; Scordamaglia, F.; Pietra, G.; Manzini, C.; Cantoni, C.; Boitano, M.; Queirolo, P.; Vermi, W.; Facchetti, F.; Moretta, A.; et al. Melanoma-associated fibroblasts modulate nk cell phenotype and antitumor cytotoxicity. Proc. Natl. Acad. Sci. USA 2009, 106, 20847-20852. [CrossRef]

10. Ozaki, Y.; Edelstein, M.P.; Duch, D.S. Induction of indoleamine 2,3-dioxygenase: A mechanism of the antitumor activity of interferon gamma. Proc. Natl. Acad. Sci. USA 1988, 85, 1242-1246. [CrossRef]

11. Jiang, T.; Sun, Y.; Yin, Z.; Feng, S.; Sun, L.; Li, Z. Research progress of indoleamine 2,3-dioxygenase inhibitors. Future Med. Chem. 2015, 7, 185-201. [CrossRef] [PubMed]

12. Munn, D.H.; Mellor, A.L. Indoleamine 2,3 dioxygenase and metabolic control of immune responses. Trends Immunol. 2013, 34, 137-143. [CrossRef] [PubMed]

13. Seok, S.H.; Ma, Z.X.; Feltenberger, J.B.; Chen, H.; Chen, H.; Scarlett, C.; Lin, Z.; Satyshur, K.A.; Cortopassi, M.; Jefcoate, C.R.; et al. Trace derivatives of kynurenine potently activate the aryl hydrocarbon receptor (ahr). J. Biol. Chem. 2018, 293, 1994-2005. [CrossRef] [PubMed]

14. Kimura, A.; Naka, T.; Nohara, K.; Fujii-Kuriyama, Y.; Kishimoto, T. Aryl hydrocarbon receptor regulates stat1 activation and participates in the development of th17 cells. Proc. Natl. Acad. Sci. USA 2008, 105, 9721-9726. [CrossRef] [PubMed]

15. Apetoh, L.; Quintana, F.J.; Pot, C.; Joller, N.; Xiao, S.; Kumar, D.; Burns, E.J.; Sherr, D.H.; Weiner, H.L.; Kuchroo, V.K.; et al. The aryl hydrocarbon receptor interacts with c-maf to promote the differentiation of type 1 regulatory t cells induced by il-27. Nat. Immunol. 2010, 11, 854-861. [CrossRef]

16. Masuda, K.; Kimura, A.; Hanieh, H.; Nguyen, N.T.; Nakahama, T.; Chinen, I.; Otoyo, Y.; Murotani, T.; Yamatodani, A.; Kishimoto, T.; et al. Aryl hydrocarbon receptor negatively regulates lps-induced il-6 production through suppression of histamine production in macrophages. Int. Immunol. 2011, 23, 637-645. [CrossRef] [PubMed]

17. Nakajima, K.; Maekawa, Y.; Kataoka, K.; Ishifune, C.; Nishida, J.; Arimochi, H.; Kitamura, A.; Yoshimoto, T.; Tomita, S.; Nagahiro, S.; et al. The arnt-stat3 axis regulates the differentiation of intestinal intraepithelial tcralphabeta(+)cd8alphaalpha(+) cells. Nat. Commun. 2013, 4, 2112. [CrossRef]

18. Litzenburger, U.M.; Opitz, C.A.; Sahm, F.; Rauschenbach, K.J.; Trump, S.; Winter, M.; Ott, M.; Ochs, K.; Lutz, C.; Liu, X.; et al. Constitutive ido expression in human cancer is sustained by an autocrine signaling loop involving il-6, stat3 and the ahr. Oncotarget 2014, 5, 1038-1051. [CrossRef]

19. Imada, K.; Leonard, W.J. The jak-stat pathway. Mol. Immunol. 2000, 37, 1-11. [CrossRef]

20. Kallal, L.E.; Biron, C.A. Changing partners at the dance: Variations in stat concentrations for shaping cytokine function and immune responses to viral infections. JAK-STAT 2013, 2, e23504. [CrossRef] [PubMed]

21. Lucas, M.; Schachterle, W.; Oberle, K.; Aichele, P.; Diefenbach, A. Dendritic cells prime natural killer cells by trans-presenting interleukin 15. Immunity 2007, 26, 503-517. [CrossRef] [PubMed]

22. Gotthardt, D.; Putz, E.M.; Straka, E.; Kudweis, P.; Biaggio, M.; Poli, V.; Strobl, B.; Muller, M.; Sexl, V. Loss of stat3 in murine nk cells enhances nk cell-dependent tumor surveillance. Blood 2014, 124, 2370-2379. [CrossRef] [PubMed]

23. Gotthardt, D.; Sexl, V. Stats in nk-cells: The good, the bad, and the ugly. Front. Immunol. 2016, 7, 694. [CrossRef] [PubMed]

24. Wang, K.S.; Frank, D.A.; Ritz, J. Interleukin-2 enhances the response of natural killer cells to interleukin-12 through up-regulation of the interleukin-12 receptor and stat4. Blood 2000, 95, 3183-3190. [PubMed]

25. Matsui, M.; Kishida, T.; Nakano, H.; Yoshimoto, K.; Shin-Ya, M.; Shimada, T.; Nakai, S.; Imanishi, J.; Yoshimoto, T.; Hisa, Y.; et al. Interleukin-27 activates natural killer cells and suppresses nk-resistant head and neck squamous cell carcinoma through inducing antibody-dependent cellular cytotoxicity. Cancer Res. 2009, 69, 2523-2530. [CrossRef] [PubMed]

26. Vosshenrich, C.A.; Ranson, T.; Samson, S.I.; Corcuff, E.; Colucci, F.; Rosmaraki, E.E.; Di Santo, J.P. Roles for common cytokine receptor gamma-chain-dependent cytokines in the generation, differentiation, and maturation of nk cell precursors and peripheral nk cells in vivo. J. Immunol. 2005, 174, 1213-1221. [CrossRef]

27. Park, A.; Lee, Y.; Kim, M.S.; Kang, Y.J.; Park, Y.J.; Jung, H.; Kim, T.D.; Lee, H.G.; Choi, I.; Yoon, S.R.; et al. Prostaglandin e2 secreted by thyroid cancer cells contributes to immune escape through the suppression of natural killer (nk) cell cytotoxicity and nk cell differentiation. Front. Immunol. 2018, 9, 1859. [CrossRef] [PubMed]

28. Somanchi, S.S.; Senyukov, V.V.; Denman, C.J.; Lee, D.A. Expansion, purification, and functional assessment of human peripheral blood nk cells. J. Vis. Exp. 2011. [CrossRef] 
29. Pietra, G.; Manzini, C.; Rivara, S.; Vitale, M.; Cantoni, C.; Petretto, A.; Balsamo, M.; Conte, R.; Benelli, R.; Minghelli, S.; et al. Melanoma cells inhibit natural killer cell function by modulating the expression of activating receptors and cytolytic activity. Cancer Res. 2012, 72, 1407-1415. [CrossRef]

30. Castriconi, R.; Cantoni, C.; Della Chiesa, M.; Vitale, M.; Marcenaro, E.; Conte, R.; Biassoni, R.; Bottino, C.; Moretta, L.; Moretta, A.; et al. Transforming growth factor beta 1 inhibits expression of nkp30 and nkg2d receptors: Consequences for the nk-mediated killing of dendritic cells. Proc. Natl. Acad. Sci. USA 2003, 100, 4120-4125. [CrossRef]

31. Krockenberger, M.; Dombrowski, Y.; Weidler, C.; Ossadnik, M.; Honig, A.; Hausler, S.; Voigt, H.; Becker, J.C.; Leng, L.; Steinle, A.; et al. Macrophage migration inhibitory factor contributes to the immune escape of ovarian cancer by down-regulating nkg2d. J. Immunol. 2008, 180, 7338-7348. [CrossRef]

32. Drake, C.G.; Jaffee, E.; Pardoll, D.M. Mechanisms of immune evasion by tumors. Adv. Immunol. 2006, 90, 51-81. [PubMed]

33. Taylor, M.W.; Feng, G.S. Relationship between interferon-gamma, indoleamine 2,3-dioxygenase, and tryptophan catabolism. FASEB J. 1991, 5, 2516-2522. [CrossRef] [PubMed]

34. MacKenzie, C.R.; Hadding, U.; Daubener, W. Interferon-gamma-induced activation of indoleamine 2,3-dioxygenase in cord blood monocyte-derived macrophages inhibits the growth of group b streptococci. J. Infect. Dis. 1998, 178, 875-878. [CrossRef] [PubMed]

35. Kai, S.; Goto, S.; Tahara, K.; Sasaki, A.; Kawano, K.; Kitano, S. Inhibition of indoleamine 2,3-dioxygenase suppresses nk cell activity and accelerates tumor growth. J. Exp. Ther. Oncol. 2003, 3, 336-345. [CrossRef] [PubMed]

36. Frumento, G.; Rotondo, R.; Tonetti, M.; Damonte, G.; Benatti, U.; Ferrara, G.B. Tryptophan-derived catabolites are responsible for inhibition of $\mathrm{t}$ and natural killer cell proliferation induced by indoleamine 2,3-dioxygenase. J. Exp. Med. 2002, 196, 459-468. [CrossRef] [PubMed]

37. Terness, P.; Bauer, T.M.; Rose, L.; Dufter, C.; Watzlik, A.; Simon, H.; Opelz, G. Inhibition of allogeneic $t$ cell proliferation by indoleamine 2,3-dioxygenase-expressing dendritic cells: Mediation of suppression by tryptophan metabolites. J. Exp. Med. 2002, 196, 447-457. [CrossRef]

38. Routy, J.P.; Routy, B.; Graziani, G.M.; Mehraj, V. The kynurenine pathway is a double-edged sword in immune-privileged sites and in cancer: Implications for immunotherapy. Int. J. Tryptophan Res. 2016, 9, 67-77. [CrossRef]

39. Platten, M.; von Knebel Doeberitz, N.; Oezen, I.; Wick, W.; Ochs, K. Cancer immunotherapy by targeting ido1/tdo and their downstream effectors. Front. Immunol. 2014, 5, 673. [CrossRef]

40. Dagenais-Lussier, X.; Aounallah, M.; Mehraj, V.; El-Far, M.; Tremblay, C.; Sekaly, R.P.; Routy, J.P.; van Grevenynghe, J. Kynurenine reduces memory cd4 t-cell survival by interfering with interleukin-2 signaling early during hiv-1 infection. J. Virol. 2016, 90, 7967-7979. [CrossRef]

41. Takaki, R.; Hayakawa, Y.; Nelson, A.; Sivakumar, P.V.; Hughes, S.; Smyth, M.J.; Lanier, L.L. Il-21 enhances tumor rejection through a nkg2d-dependent mechanism. J. Immunol. 2005, 175, 2167-2173. [CrossRef] [PubMed]

42. Xu, X.; Sun, Y.L.; Hoey, T. Cooperative DNA binding and sequence-selective recognition conferred by the stat amino-terminal domain. Science 1996, 273, 794-797. [CrossRef] [PubMed]

43. Stange, J.; Veldhoen, M. The aryl hydrocarbon receptor in innate t cell immunity. Semin. Immunopathol. 2013, 35, 645-655. [CrossRef] [PubMed]

44. Xue, P.; Fu, J.; Zhou, Y. The aryl hydrocarbon receptor and tumor immunity. Front. Immunol. 2018, 9, 286. [CrossRef] [PubMed]

45. Esser, C.; Rannug, A.; Stockinger, B. The aryl hydrocarbon receptor in immunity. Trends Immunol. 2009, 30, 447-454. [CrossRef] [PubMed]

46. Kim, S.H.; Henry, E.C.; Kim, D.K.; Kim, Y.H.; Shin, K.J.; Han, M.S.; Lee, T.G.; Kang, J.K.; Gasiewicz, T.A.; Ryu, S.H.; et al. Novel compound 2-methyl-2h-pyrazole-3-carboxylic acid (2-methyl-4-o-tolylazo-phenyl)-amide (ch-223191) prevents 2,3,7,8-tcdd-induced toxicity by antagonizing the aryl hydrocarbon receptor. Mol. Pharmacol. 2006, 69, 1871-1878. [CrossRef] [PubMed]

47. Veldhoen, M.; Hirota, K.; Christensen, J.; O'Garra, A.; Stockinger, B. Natural agonists for aryl hydrocarbon receptor in culture medium are essential for optimal differentiation of th17 t cells. J. Exp. Med. 2009, 206, 43-49. [CrossRef] [PubMed] 
48. Bedel, R.; Thiery-Vuillemin, A.; Grandclement, C.; Balland, J.; Remy-Martin, J.P.; Kantelip, B.; Pallandre, J.R.; Pivot, X.; Ferrand, C.; Tiberghien, P.; et al. Novel role for stat3 in transcriptional regulation of nk immune cell targeting receptor mica on cancer cells. Cancer Res. 2011, 71, 1615-1626. [CrossRef] [PubMed]

49. Cacalano, N.A. Regulation of natural killer cell function by stat3. Front. Immunol. 2016, 7, 128. [CrossRef] [PubMed]

50. Darnell, J.E., Jr. Stats and gene regulation. Science 1997, 277, 1630-1635. [CrossRef]

51. Schindler, C.; Darnell, J.E., Jr. Transcriptional responses to polypeptide ligands: The jak-stat pathway. Annu. Rev. Biochem. 1995, 64, 621-651. [CrossRef] [PubMed]

52. Ehret, G.B.; Reichenbach, P.; Schindler, U.; Horvath, C.M.; Fritz, S.; Nabholz, M.; Bucher, P. DNA binding specificity of different stat proteins. Comparison of in vitro specificity with natural target sites. J. Biol. Chem. 2001, 276, 6675-6688. [CrossRef] [PubMed]

(C) 2019 by the authors. Licensee MDPI, Basel, Switzerland. This article is an open access article distributed under the terms and conditions of the Creative Commons Attribution (CC BY) license (http://creativecommons.org/licenses/by/4.0/). 